\title{
The Ontology of Social Reality from Critical Realism's Perspective; Focusing on the Ideas of Margaret Archer and Andrew Sayer
}

\author{
Hossein Banifatemeh \\ Professor of Sociology, \\ University of Tabriz \\ Rob Shields \\ Professor of Sociology, \\ University of Alberta \\ Fatemeh Golabi \\ Associate Professor of Sociology, \\ University of Tabriz

\section{Fardin Ghoreishi} \\ Professor in Faculty of Law and Political Science, \\ University of Tehran

\section{Farhad Bayani} \\ Ph.D. in Sociology, University of Tabriz \\ Corresponding Author
}

Doi: $10.2478 / m j s s-2018-0048$

\begin{abstract}
This essay seeks to present the ontological perspectives of Margaret Archer and Andrew Sayer on social reality. Archer and Sayer represent two key sociologists who have taken advantage of philosophical school of critical realism for explaning the social world. Methodology is based on descriptive-analytical method. Archer introduces two notions of morphogenesis (dynamic aspect of society) and morphostasis (stability and continuation of society) and offers a new type of theoretical conflation relying on morphogenesis. Accordingly, she propounds some differences between culture, structure and action and this distinguishes her efforts from the ideas of other conflationary theoreticians, especially Anthony Giddens. Besides paying attention to the existing complexities in the nature of social reality, Sayer struggles to introduce a specific model with which one can come up with a new formulation of the process of knowledge of social reality. Sayer believes that his model provides a clearer ontology of social realities. Sayer's thought is based on the dialectical relation between the researcher (subject), research topic (object) and other researchers who work in a common linguistic community and this dialectic is among the mechanisms that give rise to the complexities of the social world.
\end{abstract}

Keywords: Social Ontology, Critical Realism, Morphogenesis, Theoretical Conflation, Social Reality

\section{Introduction}

To begin with, we seek to provide an outline of the key perspectives of critical realism as a social philosophy. Then we proceed to analyze ontological ideas of Margaret Archer and Andrew Sayer 
on social reality (social world). Critical realism is a modern philosophical school that struggles to study the social world in a new way. Though it is a conflationary approach it contains some particular intellectual features that distinguish it from other conflationary perspectives. This school has been founded by the British philosopher Roy Bhaskar. Against empiricism, critical realism does not confine itself to the phenomenal appearance of realities; rather it contends that one has to dive into deeper layers of reality. Further, this school argues that phenomenal appearances may hinder us from knowing the true existence of social reality. To have better and deeper ontological understanding of social realities, according to critical realism, one should be always ready for inspection, analysis, arrangement and criticism of our previous experiences of the aforementioned realities. We have to "be continuously ready for reforming ourselves in light of more cognitive activity such as observations, experimental evidences, interpretations, theoretical argument, dialogue and the like" (Craib and Benton, 2015: 226). In his explanation of critical realism and criticism of positivism and hermeneutics, Bhaskar makes an intelligence difference between the components and domain of knowledge.

According to Bhaskar, the process of knowledge acquisition is of two dimensions: first, an intransitive dimension that involves the world that exists outside human mind, will, and action as a social entity. The latter dimension of knowledge is totally independent of mentality and interactions of the social actors. To put it in another way, the intransitive dimension represents the outside social world that exists independently of human individuals. A second dimension of the knowledge acquisition process is the transitive dimension that stands for mental and imaginary processes of modulation, theorization and paradigms that are used by social actors for knowing social world. Bhaskar believes that this transitive dimension is of a social nature and is a function of the cultural, social and economic conditions in which a man lives (Bhaskar, 2005: 9-12).

Critical realism also has a specific perspective on the nature of social reality. According to Bhaskar, social reality as well as its respective knowledge are multilayered and multileveled. These levels and layers consist of real layer, determined and actual layer and empirical layer (Craib and Benton, 2015: 223). The real layer hosts the structures, mechanisms and processes that are not observable but represent real causal mechanisms that cause observable events and phenomena. The actual layer covers the phenomena and events that are observable and usually is confused with the real layer in recognition of causal mechanisms. All relations or phenomena on which basis a phenomenon appears after another phenomenon and we consider it a causal relation are part of the actual or determined layer of reality. The empirical layer consists of observable and tangible phenomena that are generally initiated in closed and controllable systems like laboratories. This layer is of more use when one cannot have direct access to knowledge of the actual layer and by means of the empirical layer and a number of simulations based on it s/he tries to reach the higher level (actual layer) (Bhaskar, 1986: 5). "This layer of reality is related to closed systems and it is not generally available in open systems because the course of action is different in the latter as compared to closed systems. We can use this empirical layer as a basis for simulations that help us to know the causal rules and mechanisms that might be unavailable for direct observation" (Bhaskar, 2010: 2).

As to the importance of the real layer, one should say that this layer is the most fundamental layer of the reality and though it is not as visible as the two previous layers its key role in the emergence of events and formation and development of the nature of social phenomena is undeniable. This layer provides both a basis for causal explanation and it is a fundamental structure and mechanism based on which the two concrete empirical layers become realized. "This layer of reality already exists and is in action even if we are not informed of it and in most cases, it is independent of the scientist and his scientific activities" (Bhaskar, 1986: 5).

Since the time when critical realism was introduced into sociology, it gave rise to various schools of thought the majority of which were in line. Accordingly, all these intellectual approaches and schools have been critical towards postmodernism, constructionism, and positivism. They criticize postmodernism because it does not believe in fundamental rules and social generalities. Critical realism levels objections against constructionism because the latter reduces all notions, events, institutions and social systems to theoretical constructions of thinkers who are working in different fields of science and knowledge. Positivism was taken to task due to the fact that it has 
changed the means of explanation to pure and spiritless means. "In social theory in general and sociology in particular, critical realism has embraced various ideas of Martin Hollis, William Ott, Ted Benton, Russell Keith, John Urry, Margaret Archer and Andrew Sayer" (Aghajari, n.).

This essay seeks to assay the views of Archer and Sayer on human knowledge of social reality from critical realism's point of view. In other words, our objective in this article is studying the nature of social reality based on critical realism focusing on the views of Margaret Archer and Andrew Sayer. Then our research is an effort to answer the following question: "what is the nature of social reality as conceived by Archer and Sayer?"

\section{Methodology}

The research method of the paper is based on descriptive-analytical method. In this method, researcher, in addition to describing the subject, tries to explain the subject, mechanism or causes. Descriptive-analytical method involves summarizing process information, such as the use of a theory or model in a meaningful format (Arksey and O'Malley, 2005 quoted in Levac et al., 2010: 6). The researcher needs a strong argument to explain and justify the causes. This base is provided through research in the literature and theoretical discussions and the development of propositions and general theorems on it. The investigator logically relates the details of his research problem to relevant general propositions and concludes. The remarkable point is that each of these studies has scientific value in place.

We, at first, described the main theoretical basis of critical realism's perspective, focusing on Archer and Sayer's works then, tried to explain and cognize the properties of social ontology in Archer and Sayer's thought. Especially, social ontology of Archer and social epistemology of Sayer by referring to their essential and important works.

In general, such research has a high scientific value and can lead to the discovery of facts and the creation of general knowledge and the formulation of general theorems in all sciences and human sciences.

\section{Margaret Archer: Morphogenesis and Morphostasis of Society}

Margaret Archer lays a special emphasis on the significance of ontology and epistemology of social reality in its general sense. She believes that our understanding of every social issue must be preceded by a well-grounded knowledge of social reality and the relevant methods that have to be used for acquiring this knowledge. In fact, "every practical analysis of the society not only should be informed by a dependable knowledge of social reality rather one has to know how to manage to acquire this essential knowledge" (Archer, 1995: 5).

Archer has made serious criticisms against methodological individualism and she has shown this critical mind in her Social Roots of Educational Systems (1979). She is also critical of structural approaches. She is among the most influential critics of Anthony Giddens' structuration. Although Archer is one of the sociologists who are of a conflationary approach in knowing the social reality her conflationary perspective is essentially different from that of Giddens. We will turn to this difference in coming lines. On Archer's theoretical approach, Parker writes, "Her goal was defending major sociological analyses of social systems as against methodological individualism. Later she shifted her criticisms of methodological individualism to structuration theory. In Archer's view, structuration suffers from the same inconsistencies that one finds in methodological individualism. Accordingly, structuration theory exposes the social reality to the risks that are also accompanied with the methodological individualism because this type of social analysis does not have any social and political replacement" (Parker, 2007: 116). "As opposed to methodological individualism, Archer argues that people do not act outside social-cultural and structural contexts and contrary to methodological holism, she does not confine human actions to human relations and social systems" (Porpora, 2013: 29).

Archer's explanation of social reality and world is based on a certain type of dualism that is different from philosophical dualism. To put it otherwise, according to Archer, there is no difference between the individual and society rather there is a continuous and ubiquitous interaction and 
symbiosis between these two.

"The important point here concerns the difference between Archer's analytical dualism and philosophical dualism. Philosophical dualism insists on the existential separation between individual and society while Archer rejects it. Analytical dualism claims that without human individuals, social reality is not conceivable and this reality reveals itself through human behaviors... Her antiphilosophical-dualism ontology as such can be reduced neither to individuals nor to society. But the reason for this is exactly that individual and society, structure and agency are of an undeniable coexistence and this is why we should use a dualistic method in explanation of social reality" (Parker, 2007: 118).

Archer's conflationary perspective that is christened by her as analytical dualism is different from other theoretical perspectives that present themselves as conflationary. In Culture and Agency (1996), Archer discusses three types of conflation and rejects them all. First conflation is known as downward conflation and pertains the influence that culture exerts on the actors in a way that sometimes the actors themselves are not informed of this influence. In this conflationary perspective, logical consensus of the cultural system imposes itself to the actors and sociological consensus is the result of higher level of consensus in culture as a universal unit that is conveyed to the individuals (Archer, 1996: 25-45). "This type of conflation is usually seen in Pitirim Sorokin's discussions of the dominant role and mentality of society and how the latter manages to control its institutional structures. It could be also seen in Parsons' perspective regarding the importance of common value patterns in the initiation of institutional and social consistency" (Johnson, 2008: 521).

The second type of conflation stands right in the opposing point to downward conflation and Archer calls it upward conflation and in this type of conflation, cultural consensus and unity is a product of the consensus that has been pioneered by the dominant groups in the society (Archer, 1996: 46-71). In this conflationary perspective not only culture does not have any direct influence on individuals rather it is thoroughly in the service of the interests and goals of dominant groups of societies. "This type of conflation is more seen in the ideas of neo-Marxists who believe that ideological orientation contributes to the empowerment and continuation of society's structures" (Johnson, 2008: 521).

The third type of conflation, i.e. central conflation, in which culture and interactive social and cultural paradigms are interrelated in a way that it is hard to know how these two levels can interact and influence each other (Archer, 1996: 72-96). "One can find a good example of this type of conflation in Anthony Giddens' structuration theory" (Johnson, 2008: 521-522). Archer has developed an alternative form of conflation in which the interaction between agency and culture is emphasized. By culture she refers to immaterial phenomena and ideas, while on the contrary, structure in her view alludes to material phenomena and interests. Although she contends that the latter difference is conceptual and culture and agency (structure) are intertwined in the outside social world she insists that these two are not reducible to each other and their difference has to be seriously considered (Ryan, 2005: 5).

Archer seeks to synthesize ontology, methodology, and practical theory and to this end, she introduces the notion of morphogenetic approach regarding the significance of which she writes, "methodology is usually known as an enlightening program that serves as a link between ontology and practical theory. This is what I would like to deal with; an enlightening methodology that is of a basic dimension and I call it morphogenetic approach" (Archer, 1995: 5). Archer believes that every society is of two basic features: morphogenesis and morphostasis. Each one of these two features are of a particular function and play a special role in the creation of social reality. Morphogenesis "refers to a process in which some internal changes are made in the system that not only lead to the change in overall structure of the system rather they also change the ultimate product of the system. On the contrary, morphostasis denotes the absence of these changes and is associated with stability... Both morphogenesis and morphostasis occur all the time and in every place and their influences include a set of potential structural changes that range from change in action to change in reaction and interaction and possible structural complexities" (Ryan, 2005: 5). On this compound notion, Mutch writes, "morphogenesis is consisted of two parts one of which is morpho by which Archer refers to the change in society while the other part, i.e. genetic, is used to highlight the role of agency in this change" (Mutch, 2002: 487). 
According to Archer (1995), "Morpho alludes to the fact that society does not have any predetermined form. Genetic in this context implies that there are some agents whose intentional and nonintentional actions shape the society and give it a certain form. This concept can firmly ground a triple association between ontology, methodology, and practical social theory" (Archer, 1995: 5). "Although this morphogenetic process is a product of the reciprocal actions it is of particular features that distinguish it from the reciprocal action that is predestined by some other factors" (Ryan, 2005: 5).

This corresponds Bhaskar's views regarding the emergence of social reality according to which though a social reality as a new layer is the outcome of interaction of various layers the new layer is of specific features that distinguish it from the generating layers and since it also own the features that one finds in generating layers then it is more complex than the latter layers (Bhaskar, 2010). Morphogenesis is neither a theory of a special phenomenon nor should it be used for explanation of a particular issue but "as a metatheoretical foundation, morphogenetic perspective is rather a kind of philosophy or fundamental ontology. This perspective explains the elements and components of every explanation regarding social change. This social change involves structure, culture, agency, and the general form of their internal interactions" (Porpora, 2013: 26). Archer does not have a one-sided approach in her morphogenesis. Accordingly, she does not merely consider morphogenesis a product of mutual social actions but she is also attentive to the reciprocal aspect of this relationship. Then, Archer argues, "the morphogenesis (created layer) itself exerts its influence on its generating mutual social actions in a dialectical fashion" (Ryan, 2005: 5).

The idea of morphogenesis is referring to human relative freedom and independence. To put it differently, though an individual has certain personal interests and tendencies that are influential on his/her decisions and choices it is still him/her who takes the decisions and makes the choices. "Generally, an explicit premise of the morphogenetic approach is that persons are more than just inert occupiers of subject positions, that they possess both material interests and idealistic convictions and that they act more or less coherently out of both." (Porpora, 2013: 28).

\section{Margaret Archer on the Nature of Society}

In Archer's view, society is of two domains of "cultural system" and "sociocultural layer". "Cultural system involves a range of beliefs and various forms of knowledge. These beliefs and epistemic elements may be logically consistent or inconsistent with each other. On the other hand, Archer speaks of sociocultural level in which individuals affect each other by means of these beliefs and epistemic outlooks. Interaction in this level is causal" (Johnson, 2008: 521). Archer insists on the distinctiveness of this level from analytic and theoretic perspectives. Moreover, she believes that the integrity of each one of these levels has its own particular logic. "The integrity of the cultural level has its origin in consistency and coherence while the integrity of sociocultural interactions among individuals depends on social consensus" (ibid.)

Morphogenetic perspective allows Archer to make some distinctions between certain concepts that were not noticed before her. Among these distinctions, one can refer to the difference between structure and actor, structure and culture, and objectivity and subjectivity. In our coming discussions, we will turn to these distinctions. Contrary to Giddens who contends that structure is indeed the very product of interactions of social agents and claims that structures are some sort of rules and sources that have been grounded by human agents and in doing so he reduces structure to agency, Archer is of the belief that these two, i.e. agency and structure, are by no means reducible to each other and no one of them can ever be dissolved in the other. To put it otherwise, Archer clearly argues that structure and agency are ontologically independent and distinct and structure exists as an ontological entity and cannot be reduced to actions and rules of actors. To put in clearer words, Giddens does not allow an independent and separate ontological identity for structure as against human agency while Archer totally believes in such ontologically independent identity. Archer distinguishes between these two elements by insisting on an analytical dualism "Archer originally coined the phrase analytical dualism against Giddens's duality of structure, which, redefining structure principally as rules, thereby assimilated structure into agency. In opposition, Archer's analytical dualism affirms the continuing need to maintain an analytical distinction between 
structure and agency. Although they always interrelate causally, structure and agency remain ontologically separate" (Popora, 2013: 26).

Archer protests against the fusion, conflation or identification of culture and structure and believes that these two bear certain differences that do not allow them to be identified or fused. The distinction that she makes between structure and culture has its roots in a dualism that in sociology is traditionally expressed in following ways: the material/the ideal, the objective/the subjective, the discursive/the extra-discursive. According to Archer, "In each of the pairs of contrasts just listed, culture belongs to the former and structure to the latter term." (Porpora, 2013: 27). Social dynamism, Archer argues, depends on the development of ideas, beliefs and knowledge that are embedded in culture as such and thus cultural dynamism and consequently dynamism in society are possible only via the expansion of meaning and ideal mechanisms. In this way, the concept of morphogenesis is of great importance in her thought. "Morphogenesis concerns processes that lead to the change, development and complexities of social system" (Ritzer, 2011: 333). By Archer's so-called mediating systems, social systems can sustain both their dynamism and independence of the outside world.

By her notion of morphogenesis and paying attention to the mechanisms of mobility of social systems and through introduction and development of mediating systems. Archer seeks to make it clear that though social systems are the product of interactions and actions of the social actors, when they are created in social form they can have a relative independence of these social actors and even they can make such elements and components as mediating systems inside themselves so that they can contribute to their dynamism and sustainability and also secure their independence of the surrounding environment. These social systems pave the path for individual actions and activities and at the same time they impose certain requirements and limitations on these actions. Of course, one should be mindful of the point that Archer conceives morphogenesis, morphostasis and mediating systems in relation to culture and discusses these actions and reactions within the framework of culture not actor.

Archer's notion of structure is also different from what is deemed to be a structure by Giddens. While Giddens understands structure as a set of rules and sources, Archer considers it as a set of relations. Archer's view is somewhat similar to the views of sociological holists but it has clear differences with them; holists believe that a structure is a set of relations that hold between the parts of a bigger whole but Archer limits structure to relations that only hold between actors and social agents.

As to the distinction between culture and agency, Archer contends that this distinction is both necessary and distinct. "In at least one regard, culture is what we collectively produce and agency what we individually do with it. To take one example, none of us individually produces language, which is a collective, emergent phenomenon. On the other hand, it is each of us individually who speaks through one language or another, exercising our own individual capacities as coherent selves to choose what it is we say. It is not rather, as poststructuralists would have it, that language is the agent speaking through us" (Porpora, 2013: 27).

Another type of distinction that Archer insists on is the distinction between the objective and the subjective, the discursive and the extra-discursive. He believes that it is only subjective and discursive relations that can be associated with consciousness and the latter is the condition of the emergence of these relations. Those relations that are not required to be associated with consciousness are objective and extra-discursive relations. This is to say that objective and extradiscursive relations continue to hold even if those who are involved in these relations are not conscious of them. For example, "a marriage relation exists only if the people occupying the related spousal positions understand what marriage is and what it entails. It is a relation that in this sense is ontologically subjective or, more precisely, inter-subjective. In contrast, a relation of exploitation or dependency may obtain between people or the social positions they occupy without anyone noticing it. In this sense, those relations are ontologically objective. So, the ontological distinction between the subjective and the objective or the discursive and extra discursive is another dualism the morphogenetic approach analytically maintains" (Porpora, 2013: 27).

Archer's distinction between the objective and the subjective, the discursive and the extradiscursive, and her idea that some relations are contingent upon the actors and agents' 
consciousness while there are a set of relations whose ontological status is totally independent of the consciousness of the agents of their requirements and their identity, are very similar to the distinction that Bhaskar makes between two transitive and intransitive aspects. Bhaskar also believes that the transitive aspect is contingent and conditioned on consciousness and social actions of agents while the existence of intransitive aspect is not constrained to consciousness, knowledge and social actions of the agents and it is independent of these factors.

These distinctions are among the prerequisites of morphogenesis. The key idea of Archer's morphogenesis is that social phenomena as the products of the actions and interactions of social actors are distinct from this interaction and bear certain qualities that distinguish them from their creators. These phenomena have their own particular impact on the social actors and agents whose actions and interactions are the true origins of them. They even change these social actors. This process ensures the dynamism of society. On the other hand, morphostasis is concerned with continuation not with change. This idea of Archer is very similar to Bhaskar's emergence (Bhaskar, 2010). Similarly, Bhaskar argues that from the interaction of various layers some new layers are born that have a set of qualities that are different from those that are found in the originating layers and the new layers are even more complicated.

Archer's morphogenetic model of social world is her central idea in which she deals with the relations between interactions of the actors, structure and culture, and calls it Morphogenetic Cycles. In every point of time, the existing knowledge reservoir provides a basis for sociocultural interactions within the current cultural conditions. It is through this interaction that culture is reproduced in various complicated ways (Archer, 1996: xxiv-xxvii). In her Culture and Agency (1996), Archer clearly argues that her conflationary approach is not linear and no end can be deemed for it rather it is a cycle through which the development and dynamicity of the world are ensured. To state the matter differently, after the completion of a cycle the final stage of this cycle serves as the first step in the new cycle. In other words, the final product of a cycle may be the initial stage of a new cycle. Thus conceived, morphogenetic perspective not only is not a linear dualism rather upon this perspective structural situation prepares the scene for interaction and this interaction in turn leads to further elaboration and development. Archer believes that this cycle can be transferred to cultural sphere; that is to say, cultural situation paves the ground for sociocultural interaction and this interaction itself results in cultural elaboration (Archer, 1996: xxiv). She shows these interrelations as follows,

\section{Structural conditioning $\rightarrow$ social interaction $\rightarrow$ structural elaboration \\ Cultural conditioning $\rightarrow$ sociocultural interaction $\rightarrow$ cultural elaboration}

Figure 1. The Morphogenesis of Structure and Culture.

She elaborates her theoretical model for explanation of the interaction between culture and agency and reveals more complexities in it. Accordingly, social analysis begins with a culture and primary structure. The elaboration that is given on the ideas and notions embedded in two structural and sociocultural domains that decides the quality of the interaction between these two domains. These very structural and sociocultural interactions lead to further elaboration of the structure and this elaboration can ensure structural dynamism or its stasis. As a result of this elaboration, the path is tiled for sociocultural and structural interactions in the next level (Archer, 1995: 321-323). Using this process, Archer explains the details of her main analysis of the nature of social world and the quality of its elaboration both in terms of its dynamism and in terms of its stasis. In doing so, she clearly refers to culture and structure's interactions with human agents. This model has been delineated in a book entitled Realist Social Theory: Morphogenetic Perspective (1995) as follows, 


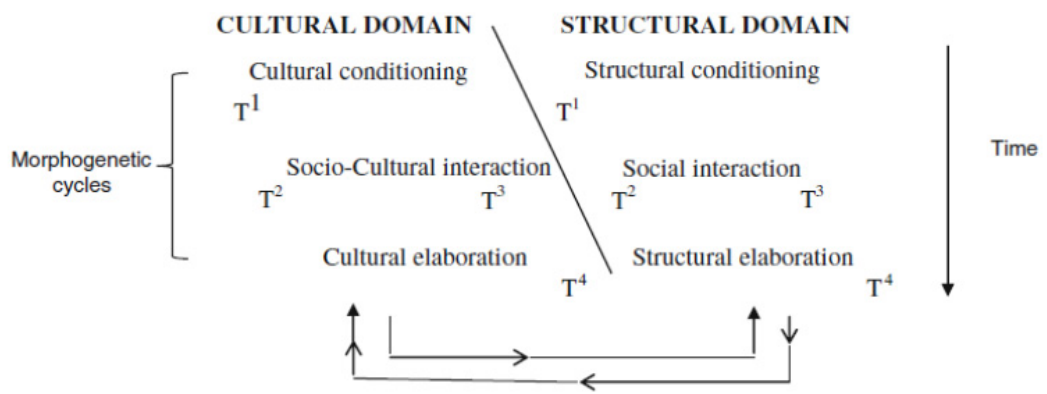

Figure 2. Morphogenesis with structure and culture together. From (Archer, 1995: 323).

Archer's morphogenetic perspective not only highlights the roles of structure and culture and their interactions rather it also recalls us the key role of human agency. Accordingly, agency is of a power that allows it to play its role in social dynamism, cultural elaboration and complexity of social world. In line with these considerations, she speaks of four types of reflexivity in her newly published The Reflexive Imperative in Late Modernity (2012) each one of which play distinctive role in mental activities of the actors and these mental activities can be related with the actions that are done by the actors in many various manners. That is to say, they may result in action or would discourage the actors from their actions. They may further the complications for the actors or trigger new doubts in the them. This quadruple reflexivity consists of 1) communicative reflexivity which includes the internal dialogues that one holds with him/herself and through these internal dialogues s/he struggles to have other people's support before proceeding to take the actions s/he intends, 2) autonomous reflexivity, in this reflexivity individual internal dialogues and self-reflections are sufficient as such and lead to action, 3) meta-reflexivity, in this reflexivity one's self-dialogues criticize his/her previous internal dialogues and s/he also critically assesses the actions s/he has taken in the society in an effective way, 4) fractured reflexivity, in this kind of reflexivity internal dialogues do not lead to effective actions rather they make the individual doubtful of action taking as such (Archer, 2013: 13).

To further illustrate these four types of reflexivity, we can use a helpful example. Suppose that we seek to manage two men's spending and their actions within this framework. When one of these two men decide to spend a huge amount of their common budget for a personal cause she refers to her/his fellow and informs him/her of his/her own internal dialogues and reflections of this decision so that before taking the action (spending the money) s/he knows the other side's reaction to the decision (communicative reflexivity). When both men reached an agreement of spending they trust the calculations and analyses they have conducted together and upon the joint approval of the action they proceed to take the action (autonomous reflexivity). If before taking any action towards the fulfilment of the planned spending they come across such speculation as have I made the right decision? Or is it necessary to spend that amount of money for this cause? They have indeed decided to reevaluate their decisions in light of critical speculations (meta-reflexivity). Here before taking any action these friends become stuck in a series of serious doubts that prevent them from handling their planned spending. This speculative doubt and confusion is what we call fractured reflexivity. Of course, it is far too clear that with more dialogues and speculations they will finally reach an agreement and this confusion will not last forever. By explaining these various modes of internal dialogue (no one of which has any priority over the others), Archer struggles to inform the readers of human capabilities in the course of evolution and dynamism of culture, society and their further elaboration, indeed.

\section{Andrew Sayer: Objects/Subjects Dialectic}

Andrew Sayer is one of the sociologists who have developed a new approach concerning social reality in general and the scope of its complexity in particular. Thus, he seeks to describe the 
structural elaboration and complexity of the social reality and struggles to come up with new ideas in this regard. His writings represent an effort toward the application of critical realism in the explanation of social reality. Since Sayer is insisting on conceptualism and meaningfulness of social phenomena, some scholars classify him as a hermeneutical thinker. However, his insistence on conceptualism and meaning in social world is not just of referring to his interest in interpretation rather it also alludes to his concerns of explanation. This is a key difference between Sayer as a critical realist and his hermeneutical counterparts. Moreover, hermeneutical approaches not only are not explanatory but they also lack a critical content while critical realism is of colorful critical content and this critical content reveals itself in criticism of method as well as in criticism of the relation between method and theory and also in criticism of social knowledge. This is why Sayer contends that to have a reliable knowledge of a given issue we must continuously revise our experiences and findings.

Sayer's fundamental criticisms are leveled against the current methods in social sciences, or it is better to say, against the way that these methods are applied in social sciences. Of course, Sayer believes that social reality would never be touch with bare hands rather we need certain methods to assist us in our path to this reality. Causal relation is among the issues that Sayer tries to provide a more exact analysis of it. "What is of paramount importance in critical realism is having a dependable knowledge of the internal mechanisms of causal relation. It is not enough just to know that $\mathrm{E}$ comes after $\mathrm{C}$. We must understand the fundamental continuous process through which C creates E" (Sayer, 1992: 107). As Sayer has rightly mentioned, in critical realism causal relation is not just a linear relation rather one needs to exactly know all the steps that have been taken by $C$ to create $E$ and reveal the underlying mechanisms and processes.

\section{Andrew Sayer's Social Ontology}

Sayer contends that knowledge occurs in two contexts of work and communicative interaction. "Work is a central phenomenon for understanding human development and growth or selfchanging. When we change our surrounding social and natural environment we are practically changing the forces and situations that make the characteristics of a society and its people.... To put it otherwise, human beings are able to change themselves.... This self-changing is fulfilled through such activities as understanding the meaning of symbols, contracts, concepts, images, rules and actions" (Sayer, 1992: 19). Sayer calls this Knowledge in Context (Sayer, 1992: 22). In a work entitled Method in Social Sciences: A Realist Approach (1992), Sayer embarks upon criticism of methods that are applied in social sciences. He believes that since social reality and knowledge arises from the context of work and communicative interaction it builds a more real and complex relation between subject and object. This is why Sayer seeks to reach more comprehensive definition of subject. Sayer is against reducing subject to an observer, thinker or researcher. He argues that subject is "a creative agent who brings about change" (ibid: 22).

To know the phenomena and issues in a given context, subjects inevitably find themselves involved in two types of interactions, "one interaction with the objects and the other with active subjects who can cause certain changes. In other words, subjects have a twofold interaction with research objects and other subjects.... Subjects cannot reach their required knowledge but via cognitive and conceptual sources that are provided for them by their society.... To put it otherwise, to know social world, we have to know each other as subjects along with the objects" (ibid: 24). In fact, Sayer struggles to introduce one of the basic principles of critical realism into social knowledge, i.e. dividing knowledge into transitive and intransitive, and to apply it in social sciences. To this end, he seeks to highlight the transitive aspect and explain its components. Thus, he turns to the role of sociocultural structures, meaning system and other social aspects that are necessary in the application of the methods and means as well as constructed social paradigms for knowing social world. Furthermore, he tries to elucidate that the intransitive aspect of knowledge is partly independent of subject's will and consciousness while transitive aspect is rooted in social interactions and daily life. It is in this sense that knowledge is considered a social product. Sayer depicts the final model of the communicative structure of formation of social knowledge as follows: 


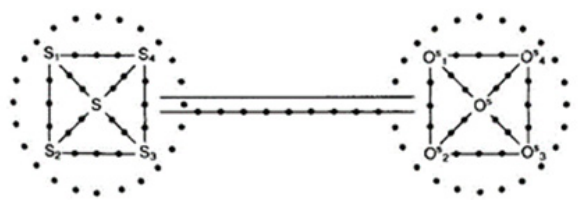

Figure 3. Andrew Sayer's Notion of Process of Social Knowledge

$S$ represents the subjects, $\mathrm{O}_{s}$ refers to the research objects, dotted circles depict the boundaries of the linguistic community and finally the dotted lines stand for social relations (Sayer, 1992: 27).

According to this model, in social knowledge, beside his/her relation with objects subject does also have certain interactions with other knowing subjects that are parts of the same language community. In other words, a subject's knowledge of an object is not independent of its mutual interactions with the object and other subjects that are engaged in knowing in the same language community. Since social knowledge is acquired via certain complex routes, Sayer argues, we need more complex research methods so as to be able to know these complex routes. In his revised model of social knowledge, Sayer alludes to the role of material phenomena and entities that do not have any meaning of their own in order to have a more integrated vision of the elements that are involved in the process of social knowledge. Of course, he believes that knowing the role of these two sets of factors in social knowledge is more complex and difficult for two reasons: 1) the unavailability of experiments makes it more difficult to use such material interventions for scientific purposes, 2) social phenomena can be changed intrinsically by learning and adjusting to the subject's understanding (Sayer, 1992: 28-29). Sayer's revised model of social knowledge is as follows,

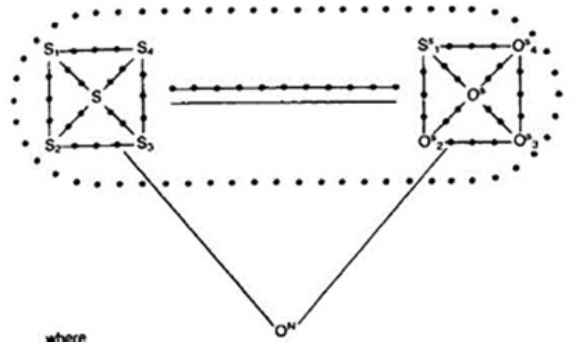

Figure 4. Andrew Sayer's Revised Model of Social Knowledge Process

$\mathrm{O}^{N}=$ material intrinsically meaningless objects, whether natural or artificial (social) (Sayer, 1992: 28).

One of the remarkable points in this model is $S^{1}$ that represents the role of a subject's understanding in changing social objects. Sayer believes that this self-changing potential of the social objects that is activated by the subject's findings doubles the complexity of social phenomenon and its knowledge. This reminds us in some way Giddensian notion of reflexivity in modern world according to which the information that social actors acquire regarding the social phenomena change their subsequent approaches and vision regarding these very phenomena. Thus, continuous reflexivity is an indispensable part of reproduction process and the change that occurs in the nature of social reality.

Considering the complexity of social reality and its knowledge, Andrew Sayer concludes that "social phenomena are intrinsically-meaningful and concept-dependent.... It obviously denies the tempting assumption that meanings are merely descriptions which are only externally applied to 
social phenomena, as they are to non-social objects.... Ideas and meanings are not the same as material objects lends some support to the mental-material and subjective-objective dualisms" (ibid: 29). Thus, he makes a clear distinction between material and social phenomena. Accordingly, social phenomena are intrinsically meaningful and there are obvious examples of these intrinsically meaningful phenomena like ideas, beliefs, concepts and knowledge that man uses in the society. Moreover, these ideas are social. "Not only they are created in the society but they are also about the society" (ibid: 30 ). The difference between social and natural phenomena, according to Sayer, lies in the fact that the former is meaningful and concept-dependent while the latter is not. Social phenomena's being meaningful and concept-dependent implies that they let the meaning in and absorb it but material phenomena do not have this special possibility and are impervious to the meanings that are ascribed to them. This is why we have to use interpretative method to understand social phenomena and their meanings.

In his Realism and Social Sciences (2000), Andrew Sayer turns to the interaction between agency and structure and argues that we cannot occupy ourselves with one of them and ignore the other, because in social world we always see their interaction in social phenomena and event. Of course, this interaction takes different forms in different contexts. "Agency and structure also have to be articulated. There are approaches which emphasize agency and are relatively silent on structure; much archival research falls into the trap of reducing the relevant context to the interactions among key actors, ignoring such matters as economic change and changes in public opinion, and the structures within which agents act" (Sayer, 2000: 6). In fact, the context in which the agent is engaged with its social actions is the transitive aspect of knowledge that is totally social and cultural and it is a function of the cultural and social conditions which prevail the life-world of the actors. Accordingly, the hypotheses, paradigms and models that they create for producing their desired knowledge of a certain reality. This is the reason why Sayer insists on the necessity of paying attention to the contexts in which social interactions take form because it is this very social aspect that ensures the social dimension of knowledge. In other words, social conditions of actors both qualitatively and quantitatively are dependent upon this social aspect. Thus, we cannot ignore the role of structures in the production of social knowledge.

Though social realities are the outcome of actions of the social actors, Sayer asserts, they have a relative independence after their creation and thus they can be considered as independent phenomena. "Although social realities cannot exist without the actions of their creators they are usually of an independent existence as compared to the individual or individuals who are studying them" (Sayer, 2010: 49). Here Sayer implicitly admits that though social actors are in charge of the production of social phenomena and realities and the latter are dependent on them in this respect, when these social phenomena are produced they have a relative independence that allows them to be involved in the process of social reproduction of their own identities. This is one of the most important outcomes of Sayer's ontology.

As to the role of actors in production and changing social events, Sayer contends that actors are actively and effectively working along with the actors. These social events cannot be only the products of their surrounding social structures rather these structures need the contributions of social actors for the reproduction of the events. "Social structures do not endure automatically, they only do so where people reproduce them; but, in turn, people do not reproduce them automatically and rarely intentionally.... Hence, while certain actions are only possible within particular social structures, the existence of the latter depends upon the continued (contingent) execution of those actions" (Sayer, 1992: 96). Like Sayer, Bhaskar also believes that reproduction of these social structures is done mostly in an unintentional fashion. "People do not marry to reproduce the nuclear family or work to reproduce the capitalist economy. Yet it is nevertheless the unintended consequence (and inexorable result) of, as it is also a necessary condition for, their activity" (Bhaskar, 2005: 38).

Accordingly, we can feasibly conclude that Sayer (and even Archer) believe in the interaction of agency and structure but the question is that what is the difference between critical realism and other conflationary approaches that similarly insist on the interaction of these two key elements of agency and structure? To answer this question, we need to refer to the obvious difference that Aqajari has mentioned in this regard, "Critical realists believe that one cannot separate the closed 
system of society, structure, from its open system, agency. In his Structuration of Society (1984), Giddens retains this difference both in research and in society but critical realists believe that in open system of society these two elements are inseparable and it is indeed by using the abstract techniques and methods of research that we separate these two from each other. Since closed system for social science is not in the laboratory but in society then closed system is not that closed for the social science. Paying attention to this difference between research and reality helps us not to reduce one of them to the other" (Aqajari, d.: 19).

This difference between the critical realism and other conflationary approaches leads us to the important conclusion that even the causal relations or basic mechanisms that are discovered in laboratorial conditions of a closed system act differently when they are brought out of the closed system and introduced into the open system. They act differently because they are interacting with different mechanisms that are at work in an open society. To put it otherwise, critical realism insists that the mechanisms that we discover through research and intellectual efforts have to be studied with utmost precision and critical sensitivity as these mechanisms and causal processes and interactions can act differently when they appear on social scene. For example, Marx claimed that material forces of production in every production system are continuously changing; these material forces refer to the natural forces that can be controlled and managed by technology. Social relations of production (the relations that human individuals develop with their fellows so as to be able to use materials and technologies for fulfilment of their production goals) should change with the transformation of material forces and means of production in society, but in a point these production relations do not change and challenge the current ownership relations (owners/nonowner divisions). When society reaches this point the representatives of growing social classes find the existing ownership relations in conflict with their further evolution and they become revolutionary and revolt against these relations and struggle to replace them with other types of relations.

However, as history has clearly attested, Marx's promised proletarian revolution never happened. Skilled workers (blue collar workers) who owned certain skills in industrial production brought about a gap among Marxian proletariat that was deemed as an integrated social union. Although these skilled workers did not own anything in their workplace, they had instead a secured and dependable income with which they could manage their family. This distinguished them from the proletariat and Lumpenproletariat. Even some of these skillful workers succeeded to own certain means of production though in a limited way. Their activities guaranteed the stability of capitalist regime. Of course, the capitalist regime took certain measures like insurance and retirement services reduced the existing tensions. The children of workers were given the opportunity to receive education and promoted to higher classes. In fact, capitalism after establishing itself provided numerous opportunities for various social classes. If we are to analyze this issue based on the critical realism, we should say that Marx's idea of revolution due to the existing tension between transforming material relations and permanent social relations of production, was indeed a historical analysis in a closed research atmosphere but when it was brought to the openness of the society it interacted with other mechanisms like the growth of bluecollar workers and this interaction resulted in different consequences.

\section{Conclusion}

This essay sought to present the ideas of Margaret Archer and Andrew Sayer as two key social thinkers who have struggled to explain the social world and reality from the perspective of critical realism. ${ }^{1}$ Generally speaking, Archer's theory can be summarized in four key points: firstly, cultural system is composed of elements that have logical relations. Secondly, cultural system has a causal impact on sociocultural system. Thirdly, there is a causal relation between the individuals who are active in sociocultural level. Fourthly, transformations that occur in the sociocultural level leads to the completion of cultural system (Ritzer, 2003: 713).

Archer and critical realism in general offer new approach for explanation of the nature of social

${ }^{1}$ Of course, there are other remarkable figures of this bent such as Ted Benton, Andrew Kolier, Douglas Porpora, Tony Lawson, Allan Nory, Hew Lacy, and William Outweight (see Archer et al., 1998). 
reality. This approach insists on the interrelations of agency, culture and structure, and it seeks to elaborate on the details of these interrelations. Accordingly, with an exact illustration of the difference between culture and structure and with an explanation of the quality of the interaction of these two elements with agency critical realism has succeeded to present a more precise outlook of social world. By introducing the innovative idea of morphogenetic cycle, this perspective seeks to analyze the process of creation and transformation of social world in a way that the interactions between cultural, social and sociocultural spheres can be exactly discerned. Then, it struggles to cast light on social aspects of the world and highlight those aspects of the social world that are relatively independent of social actors and even exert a certain kind of influence on these actors.

Andrew Sayer also insist on the complexities of social world and the strategies that have to be adopted in knowing these complexities of the social world. He invites us to revise the traditional methods of social sciences so as to find better methods for knowing the existing social complexities in a more efficient fashion. One can summarize Sayer's theory by quoting his 8 key remarks in his Method in Social Science: A Realist Approach concerning the nature of social world and its relevant epistemology:

1- The world exists independently of our knowledge of it.

2- Our concept of that world is fallible and theory-laden. Concepts of truth and falsity fail to provide a coherent view of the relationship between knowledge and its object. Nevertheless, knowledge is not immune to empirical check, and its effectiveness in informing and explaining successful material practice is not mere accident.

3- Knowledge develops neither wholly continuously, as the steady accumulation of facts within a stable conceptual framework, not wholly discontinuously, through simultaneous and universal changes in concepts.

4- There is necessity in the world; objects- whether natural or social - necessarily have particular causal powers or ways of acting and particular susceptibilities.

5- The world is differentiated and stratified, consisting not only of events, but objects, including structures which have powers and liabilities, capable of generating events. These structures may be present where, as in the social world and much of the natural world, they do not generate regular patterns of events.

6- Social phenomena such as actions, texts and institutions, are concept-dependent. We therefore have not only to explain their production and material effects but to understand, read or interpret what they mean. Although they have to be interpreted by starting from the researcher's own frames of meaning, by and large they exist regardless of researcher's interpretations of them. A qualified version of 1 therefore still applies to the social world. In view of 4-6, the methods of social science and natural science have both differences and similarities.

7- Science or the production of any other knowledge is a social practice. For better or worse (not just worse), the conditions and social relations of the production of knowledge influence its content. Knowledge is also largely - though not exclusively - linguistic, and the nature of language and the way we communicate are not incidental to what is known and communicated. Awareness of these relationships is vital in evaluating knowledge.

8- Social science must be critical of its objects. In order to be able to explain and understand social phenomena we have to evaluate them critically (Sayer, 2010: 4).

\section{References}

Archer, M., 1979. Social Origins of Educational Systems. London: Sage.

Archer, M., 1995. Realist Social Theory: the Morphogenetic Approach. Cambridge University Press.

Archer, M., 1996. Culture and Agency: The Place of Culture in Social Theory, Revised edition. Cambridge: University of Cambridge Press.

Archer, M., 2012. The Reflexive Imperative in Late Modernity. Cambridge; Cambridge University Press.

Archer, M., Bhaskar, R., Collier, A., Lawson, T. \& Norrie, A., 1998. Critical Realism: Essential Readings, eds. London: Routledge.

Arksy, H., and O'malley, L., 2005. Scoping studies: towards a methodological framework. International Journal Social Research Methodology, 8(1): 19-32. 
Craib, I., \& Benton, T., 2015. Philosophy of Social Sciences: Philosophical Foundations of Social Thought, translated into Persian by Shahnaz Mosammaparast and Mahmoud Motahed, Fifth Impression, Tehran, Agah Publication.

Bhaskar, R., 1986. Scientific Realism and Human Emancipation. London: Verso.

Bhaskar, R., 2005. The Possibility of Naturalism: A Philosophical Critique of the Contemporary Human Sciences. Third edition. London: Routledge.

Bhaskar, R., 2010. Contexts of interdisciplinarity: interdisciplinarity and climate change, 1-24. In R., Bhaskar, C., Frank, K., G., Høyer, P., Næss and J., Parker, eds, Interdisciplinarity and Climate Change Transforming knowledge and practice for our global future. London: Routledge.

Giddens, A., 1984. The constitution of society. Cambridge, MA: Polity.

Jafari R. M., 2008. Reconciliation of Realism and Constructionism, Tehran, Institute of Cultural and Social Studies.

Levac, D., Colquhoun, H., and O'Brien, K. K., 2010. Scoping Studies: Advancing the Methodology. Implementation Science, 5(69): 1-9.

Mutch, A., 2002. Actors and Networks or Agents and Structures: Towards a Realist View of Information Systems. Organization, 9(3), 477-496.

Parker, J., 2007. Structuration, translated by Hossein Qazyan, Tehran, Nashre Ney.

Porpora, D. V., 2013. Morphogenesis and Social Change, 25-38. In M, Archer, ed. Social Morphogenesis. Springer.

Ritzer, G., 2003. Social Theory in Contemporary World, translated by Mohsen Thulathi, Theran, Elmi Publication.

Ritzer, G., 2011. Sociological Theory. Eighth edition. New York: McGraw- Hill.

Ryan, M., 2005. Agency-Structure Integration, 5-6. In G, Ritzer, ed. Encyclopedia of Social Sciences. Thousand Oaks. California: Sage Publication.

Sayer, A., 1992. Method in Social Science: A Realist Approach. 2nd edition. London: Routledge

Sayer, A., 2000. Realism and Social Science. London: Sage.

Sayer, A., 2010. Method in Social Science: A Realist Approach. Revised second edition. London: Routledge. 